\title{
TRIANGLE operation for borderline resectable pancreatic cancer in total pancreatectomy
}

\author{
Shuyu Zhai", Zhen Huo", Yue Wang", Hao Qian, Shulin Zhao, Yusheng Shi, Yuanchi Weng, \\ Xiaxing Deng, Baiyong Shen \\ Department of General Surgery, Ruijin Hospital Affiliated to Shanghai Jiao Tong University School of Medicine, Shanghai 200025, China \\ Contributions: (I) Conception and design: Y Weng, X Deng, B Shen; (II) Administrative support: None; (III) Provision of study materials or patients: \\ None; (IV) Collection and assembly of data: H Qian, S Zhao, Y Shi; (V) Data analysis and interpretation: Z Huo, S Zhai, Y Wang; (VI) Manuscript \\ writing: All authors; (VII) Final approval of manuscript: All authors. \\ \#These authors contributed equally to this work. \\ Correspondence to: Baiyong Shen; Xiaxing Deng; Yuanchi Weng. Department of General Surgery, Ruijin Hospital Affiliated to Shanghai Jiao Tong \\ University School of Medicine, 197 Ruijin 2 Road, Shanghai 200025, China. Email: shenby@shsmu.edu.cn; wyuanchi@126.com; kejiadxx@hotmail.com.
}

Background: Pancreatic cancer is a highly aggressive cancer featured by early metastasis and multiple chemoresistance. Surgical resection remains the only way for the radical cure of pancreatic cancer. The aim of this study was to assess the safety, feasibility and oncological effect of the Heidelberg TRIANGLE operation in total pancreatectomy (TP) for borderline resectable pancreatic cancer (BRPC).

Methods: Patients with BRPC eligible for TP were selected and underwent total pancreatectomy with Heidelberg TRIANGLE operation. Sharp dissection was applied to separate tumor and involved artery. Then we completely dissected the soft tissues surround celiac axis (CA) and superior mesenteric artery (SMA) in each case. If superior mesenteric vein (SMV) or portal vein (PV) were invaded by the tumor, resection and reconstruction of veins were performed. Operation time, blood loss, post-operative complications, perioperative mortality, number of lymph node examined and R0 resection rate were collected and analyzed. Results: Nine BRPC patients underwent TRIANGLE operation in TP. No perioperative death occurred. 3 cases developed postoperative complications: biliary leakage and colon fistula in 1 case and lymphatic leakage in 2 cases. The R0 resection rate of operation was $88.89 \%(8 / 9)$.

Conclusions: For patients with BRPC, upfront surgery should be encouraged when they were unwilling or unable to received neoadjuvant therapy. Especially for those patients with artery involvement eligible for TP, TRIANGLE operation can help to achieve arterial sparing resection. Thus, the risk of postoperative hemorrhage for vascular reconstruction and skeletonization can be reduced. After postoperative adjuvant therapy, the prognosis is acceptable.

Keywords: Pancreatic cancer; general surgery; pancreatectomy

Submitted Oct 02, 2018. Accepted for publication Sep 23, 2019.

doi: $10.21037 /$ tcr.2019.09.50

View this article at: http://dx.doi.org/10.21037/tcr.2019.09.50

\section{Introduction}

Due to its location depth and asymptomatic feature in early stage, pancreatic cancer has often developed into advanced stage when diagnosed (1). Therefore, the treatment of borderline resectable or locally advanced pancreatic cancer is of great importance. The definition of borderline resectable pancreatic cancer (BRPC) and locally advanced pancreatic cancer (LAPC) is based on the relationship of tumor and its nearby main blood vessels $(2,3)$.

This study was conducted for patients with BRPC that required total pancreatectomy (TP) and combined a previously reported surgical procedure, TRIANGLE operation (4), to evaluate its perioperative clinical outcomes, effectiveness of radical resection and prognosis of patients. 

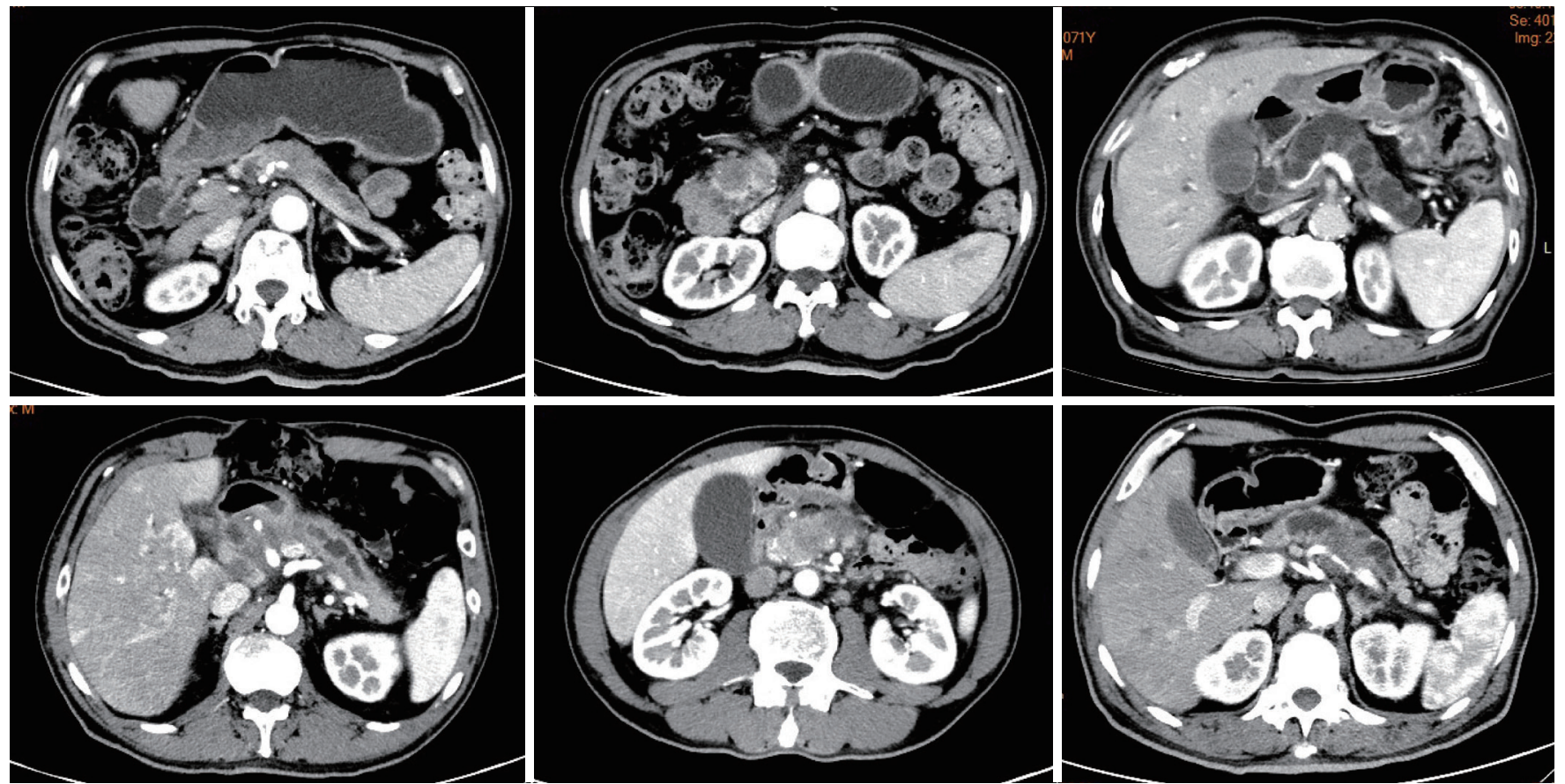

Figure 1 CT scan of patients eligible for TRIANGLE operation.

\section{Methods}

\section{Patients}

Patients who met the following criteria were collected and retrospectively analyzed: (I) Diagnosed as BRPC by multidisciplinary treatment (MDT) (5). (II) Refused to receive the neoadjuvant therapy and asked for surgery due to the unwillingness to take the risk of down-staging failure after neoadjuvant therapy. (III)Without distant metastasis. (IV) Diagnosed by CT scan (Figure 1) as large malignant tumor (postoperative pathological diagnosis of pancreatic ductal adenocarcinoma, PDAC) that has invaded pancreatic neck, intraductal papillary mucinous tumor (IPMT) involved the whole pancreas, multifocal and multi-segment pancreatic cancer, and other situations which were eligible for TP (6).

\section{Surgery procedure}

Resectability assessment: Explore the abdominal cavity to exclude distant metastasis and make the Kocher maneuver. Then, we cut off the gastrocolic ligament and dissect the inferior border of pancreas. When we found SMV, separate its left side and then explore the SMA and CA. Resectability was evaluated according to NCCN guidelines (version 3.2017) (7).

Total pancreas resection: For resectable tumor, without dissecting pancreatic neck, free the pancreatic head and duodenum following the procedure of pancreaticoduodenectomy (PD), Then, according to distal pancreatectomy (DP), free the spleen and pancreatic body and tail from distal to proximal till meet the pancreatic head. At the same time, the surrounding lymph nodes were dissected.

Clearance of Heidelberg triangle (4): a complete skeletonization of artery was required. The surgery should be performed in the adventitial level. Arterial skeletonization was performed, which included the excision of the sheath of SMA, CA, abdominal aorta and root of common hepatic artery (CHA), and the dissection of lymphoid and fat tissue along the arterial adventitia. The resection and reconstruction of SMV or PV could be done when either of them was invaded by tumor, vein reconstruction including direct anastomosis or artificial vascular bypass. At last, the complete dissection of lymphoid and fat tissue, as well as nerve tissue in Heidelberg triangle was accomplished-complete skeletonization around CA, the origin of SMA, PV/SMV and CHA (Figure 2).

Anastomosis: choledochojejunostomy and gastrojejunostomy were performed. When operation 

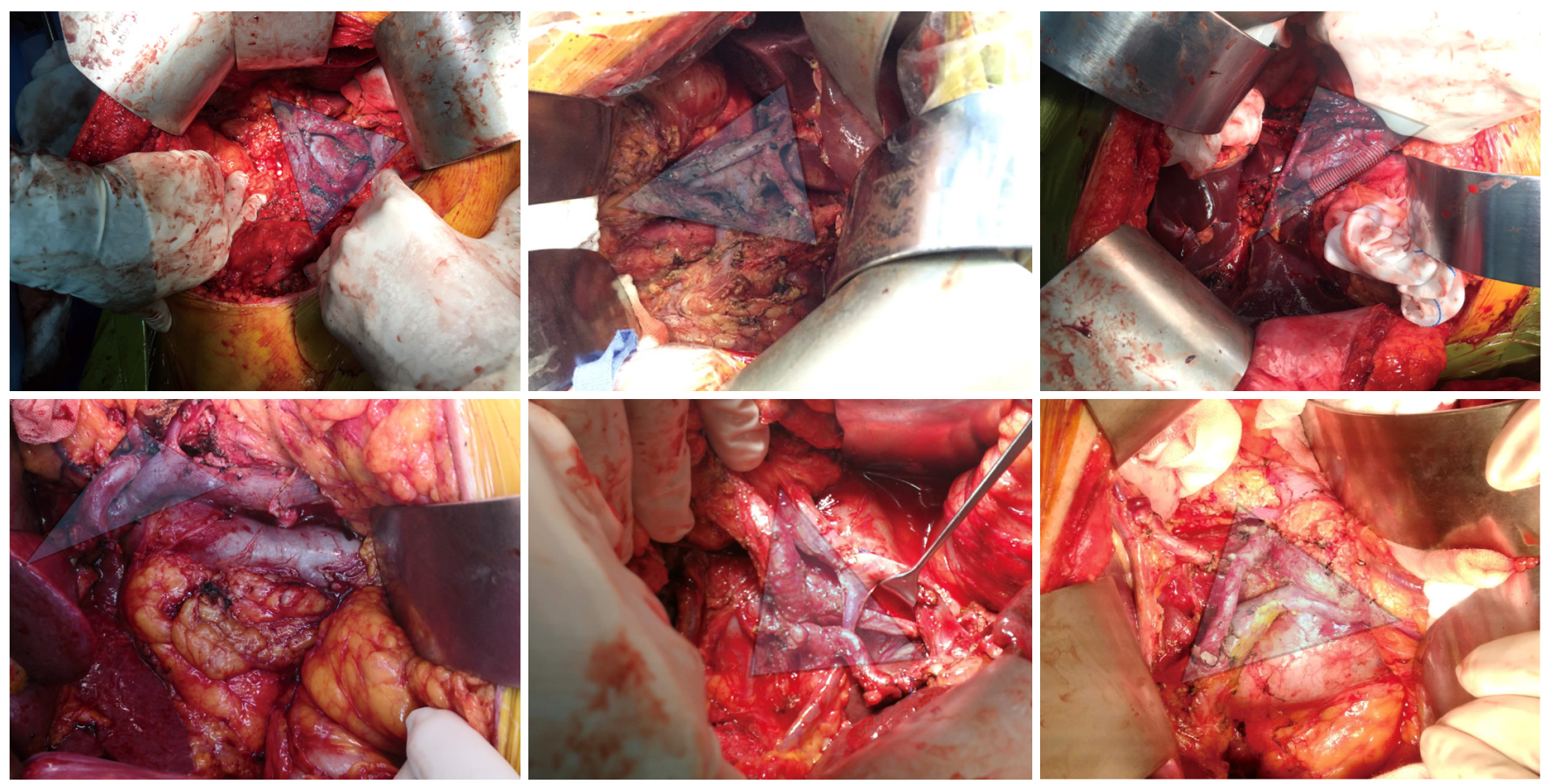

Figure 2 Pictures taken during surgery. The triangle indicates CA, SMA and PV/SMV, which are involved in TRIANGLE operation. CA, celiac axis; SMA, superior mesenteric artery; SMV, superior mesenteric vein; PV, portal vein.

finished, drainage tubes were placed beside the bilioenteric anastomosis and in splenic fossa respectively.

Surgerical specimen management: The surgical margin of bile duct, uncinate process, retroperitoneum, stomach and jejunum, along with the location of lymph nodes, were marked. The posterior peritoneal resection margin was defined as the intraoperative removal of a piece of connective tissue closely adjacent to the celiac trunk. All specimens received pathological examination (8).

\section{Patient data}

Age, sex, body mass index (BMI), American Society of Anesthesiologist's classification (ASA) and Eastern Cooperative Oncology Group (ECOG) stages were collected as baseline parameters. All patients received CT and MRI scan before surgery. Operative parameters included operation time, blood loss and details of the surgical procedure. International Study Group of Pancreatic Surgery (ISGPS) $(9,10)$ and the Clavien-Dindo classification (11) were used to classify the postoperative morbidity. Leeds protocol, in which $\mathrm{R} 0$ resection is defined as a minimum distance of $1 \mathrm{~mm}$ of tumor cells to the resection margin (8), was used to perform histopathological examination of the samples. Informed consent from all participating patients and approval from the Ethics Committee of Shanghai Ruijin Hospital (No.172 in 2018) were obtained to conduct this research.

\section{Statistics}

Results are presented in the form of mean $\pm \mathrm{SD}$, including perioperative parameters, postoperative parameters and postoperative complications. Data was analyzed using GraphPad Prism 7.

\section{Results}

From Aug 2017 to Jun 2018, 9 patients with BRPC underwent TRIANGLE operation in TP (Table 1). 8 patients underwent one step TP. 1 patient underwent TP of the remnant pancreas after DP due to local recurrence. According to imaging examination, SMA or CA was encased by the tumor less than half in circumference in 5 patients. The mean age of the patients was 63.3 years old and 7 of them were male. Six patients were defined as ASA 1, the rest 3 patients as ASA 2. The mean BMI was 21.5. ECOG performance status was 0 or 1 for all patients. Four patients 
Table 1 Baseline parameters

\begin{tabular}{lc}
\hline Characteristics & Number \\
\hline Age & $63.33 \pm 10.1$ \\
Sex (M/F) & $7: 2$ \\
BMI & $21.57 \pm 2.568$ \\
ASA class $\leq 2$ & 9 \\
ECOG $\leq 1$ & 9 \\
Diabetes mellitus & 4 \\
Hypertension & 3 \\
Cardiopulmonary dysfunction & 0 \\
\hline
\end{tabular}

BMI, body mass index; ASA, American Society of Anesthesiologist; ECOG, Eastern Cooperative Oncology Group.

had diabetes history and 3 suffered hypertension. No one had cardiopulmonary dysfunction.

Median blood loss was $633 \mathrm{~mL}$ (range, 200-1,500 mL), median operation time was $383 \mathrm{~min}$ (range, 240-660 min) and packed red blood cells (2-6 units) or fresh frozen plasma (4-10 units) was transfused to 8 patients during surgery. Median tumor diameter was $7 \mathrm{~cm}$ (range, $3.3-8 \mathrm{~cm}$ ). The perioperative data was listed in Table 2 . Compared to the perioperative data from surgery without TRIANGLE operation in recent years, despite longer operating time and more blood loss, much more lymph nodes and positive lymph nodes were collected (Figure 3).

In histopathological examination, 8/9 patients got an $\mathrm{R} 0$ resection. One case of positive resection margin was found in retroperitoneal resection margin. Perineural and lymphovascular invasion were observed in all of the 9 patients. The number of lymph node collected in surgery ranged from 19 to 44 . N1 stage was found in 4 patients, N2 in 5 patients.

As is shown in Table 3, median postoperative hospital stay was 29 days (range, 17-42 days). Two patients suffered diarrhea after surgery. No one had postoperative bleeding, pancreatic fistula or hypokalemia. No postoperative mortality occurred, surgical morbidity was observed in $3 / 9$ patients, include 2 cases of chyle leak $(n=2)$, and 1 case of bile leakage combined with colon fistula who received re-operation. Complication of 2 patients was classified as Clavien-Dindo grade 2 and 1 patient as grade 4 with the need for ICU care. No readmission occurred.

The median follow-up days was 8.9 months (range, 5-10 months). Two patients suffered tumor recurrence (1 patient with liver metastases, 1 with lung recurrence) after 4 months. Five patients have been dead until now. The median survival was 205 days (range, 130-309 days).

\section{Discussion}

The morbidity of pancreatic cancer has been increasing in recent years. Many patients are diagnosed with vascular invasion or distant metastasis. How to effectively treat BRPC is a breakthrough point in improving the overall therapeutic effect of PDAC, and also should be a priority for doctors (12). Radical resection is now regarded as the only way to possibly cure the pancreatic cancer (13), but surgical resection of BRPC is still controversial: (I) Whether to resect the tumor largely depends on preoperative imaging diagnosis, which unfortunately cannot always provide real resectability (14) and can not distinguish tumor invasion from fibrosis caused by inflammation (15). Despite the wide application of MDT in the treatment of pancreatic cancer (16), there is still a dilemma where you may lose the opportunity of surgery for a resectable tumor or excise an unresectable tumor for which $\mathrm{R} 0$ resection can not be achieved. For example, especially those patients who are considered unresectable because of CA, CHA or SMA encasement (no more than half in circumference) can get R0 resection with surgeon's effort. (II) For the treatment of BRPC, neoadjuvant therapy is highly recommended in guidelines especially in Europe and America (17). Some treatment reported has greatly improved the resection rate and prognosis of these two types of tumor (18-21).

However, some patients, whose tumor fails to downstage but develops after neoadjuvant therapy, lose the opportunity to undergo radical resection of the tumor. In addition, unlike patients in Europe and America, many Asian patients cannot tolerate chemotherapy, and cannot endure a complete neoadjuvant therapy. Secondly, this study comes from China, and patients are more willing to receive traditional Chinese medicine treatment. Finally, most patients are unable to afford the high cost of neoadjuvant therapy. Hence, many patients have a strong wish of receive "surgery first" treatment. For those patients with artery encasement, when they choose "surgery first", the dissection of the triangle region including CA, SMA and PV (Heidelberg triangle) and skeletonization of these vessels may decrease the local recurrence. In fact, those patients in the study do not appear local recurrence after surgery.

For patients of BRPC who received "surgery first" treatment, En-bloc resection, R0 resection, complete lymph nodes and nerves dissection, good postoperative recovery, 
Table 2 Perioperative and pathological data

\begin{tabular}{|c|c|c|c|c|c|c|c|c|c|}
\hline No. & 1 & 2 & 3 & 4 & 5 & 6 & 7 & 8 & 9 \\
\hline Surgery & $\begin{array}{l}\text { One-step } \\
\text { TP }\end{array}$ & $\begin{array}{c}\text { One-step } \\
\text { TP }\end{array}$ & $\begin{array}{c}\text { One-step } \\
\text { TP }\end{array}$ & $\begin{array}{l}\text { One-step } \\
\text { TP }\end{array}$ & $\begin{array}{l}\text { One-step } \\
\text { TP }\end{array}$ & $\begin{array}{l}\text { One-step } \\
\text { TP }\end{array}$ & $\begin{array}{l}\text { One-step } \\
\text { TP }\end{array}$ & $\begin{array}{l}\text { One-step } \\
\text { TP }\end{array}$ & $\begin{array}{c}\text { Remnant } \\
\text { TP }\end{array}$ \\
\hline $\begin{array}{l}\text { Operating } \\
\text { time (min) }\end{array}$ & 240 & 420 & 660 & 200 & 420 & 300 & 550 & 240 & 420 \\
\hline Reoperation & No & No & No & No & No & Yes & No & No & No \\
\hline $\begin{array}{l}\text { Pathological } \\
\text { classification }\end{array}$ & PDAC & PDAC & PDAC & PDAC & IPMT & PDAC & IPMT & PDAC & PDAC \\
\hline Tumor size $(\mathrm{cm})$ & 8.1 & 8.4 & 6.1 & 3.8 & 13.5 & 3.5 & 8.6 & 5.6 & 4.2 \\
\hline $\begin{array}{l}\text { Perineuronal } \\
\text { invasion }\end{array}$ & Yes & Yes & Yes & Yes & Yes & Yes & Yes & Yes & Yes \\
\hline $\begin{array}{l}\text { TNM stage } \\
\left.\text { (AJCC } 8^{\text {th }}\right)\end{array}$ & III & III & III & III & III & III & III & III & III \\
\hline $\begin{array}{l}\text { Vein resection and } \\
\text { reconstruction }\end{array}$ & & PV & PV & & PV & PV & PV & PV & PV \\
\hline $\begin{array}{l}\text { Postoperative } \\
\text { adjuvant therapy }\end{array}$ & $\mathrm{TCM}$ & GS & GS & GEM & GS & $\mathrm{TCM}$ & S-1 & GS & $\mathrm{TCM}$ \\
\hline
\end{tabular}

SMA, superior mesenteric artery; SMV, superior mesenteric vein; PV, portal vein; SV, splenic vein; CA, celiac axis; PDAC, pancreatic ductal adenocarcinoma; IPMT, intraductal papillary mucinous tumor; LNR, lymph node ratio; AJCC, The American Joint Committee on Cancer. GEM, Gemcitabine, $1,000 \mathrm{mg} / \mathrm{m}^{2}$ (i.v.) at $1^{\text {st }}, 8^{\text {th }}, 15^{\text {th }}$ day of chemotherapy; GS, Gemcitabine $+\mathrm{S}-1,1,000 \mathrm{mg} / \mathrm{m}^{2} \mathrm{gemcitabine}\left(\right.$ i.v.) at $1^{\text {st }}, 8^{\text {th }}$ day of chemotherapy and $60 \mathrm{mg} / \mathrm{m}^{2} \mathrm{~S}-1$ (po, bid) from $1^{\text {st }}$ to $14^{\text {th }}$ day of chemotherapy; $\mathrm{S}-1,60 \mathrm{mg} / \mathrm{m}^{2} \mathrm{~S}-1$ (po, bid) from $1^{\text {st }}$ to $14^{\text {th }}$ day of chemotherapy.

appropriate and timely adjuvant therapy are beneficial to patients' survival. Our study was aimed at patients with BRPC eligible for TP, and based on surgical skills such as vascular skeletonization and vessel reconstruction. Therefore, we suggest that the "Heidelberg TRIANGLE operation" should be added to TP as a key procedure, which will help to increase the number of lymph nodes examined, reduce complications rate and have better radical treatment efficacy for BRPC.

TP plays an important role in the treatment of pancreatic cancer for several reasons: (I) TP is the only surgery for the radical resection of pancreatic cancer, which cannot be achieved by PD or DP. (II) Multifocal and multi-segment pancreatic cancer, as well as IPMT that involves the entire pancreas, require TP. (III) TP is helpful to the dissection of surrounding lymph nodes and nerves, and improves the long-term prognosis of pancreatic cancer. (IV) Fistula of pancreatic stump and anastomotic leak can be prevented by TP.

When Heidelberg TRIANGLE operation is performed in TP, the tissue around SMA, CA, PV and CHA can be fully exposed (Figure 2). Also we can control the potential of bleeding when dissecting near the vessels, which helps to open the arterial sheath and strip the lymphoid tissue, soft tissue and nerves along the adventitia. Besides, this operation provides enough space for operator to reconstruct the veins and reduces the time of portal vein occlusion. Moreover, it exerts great impact on the radical resection the negative rate of surgical margin and long-time survival of patients of pancreatic cancer $(4,6)$.

This group of patients did not receive neoadjuvant therapy. As a result, there is less fibrosis of tissue and adventitia induced by chemotherapy, which can help us prevent unintended arterial injuries. The second remarkable 

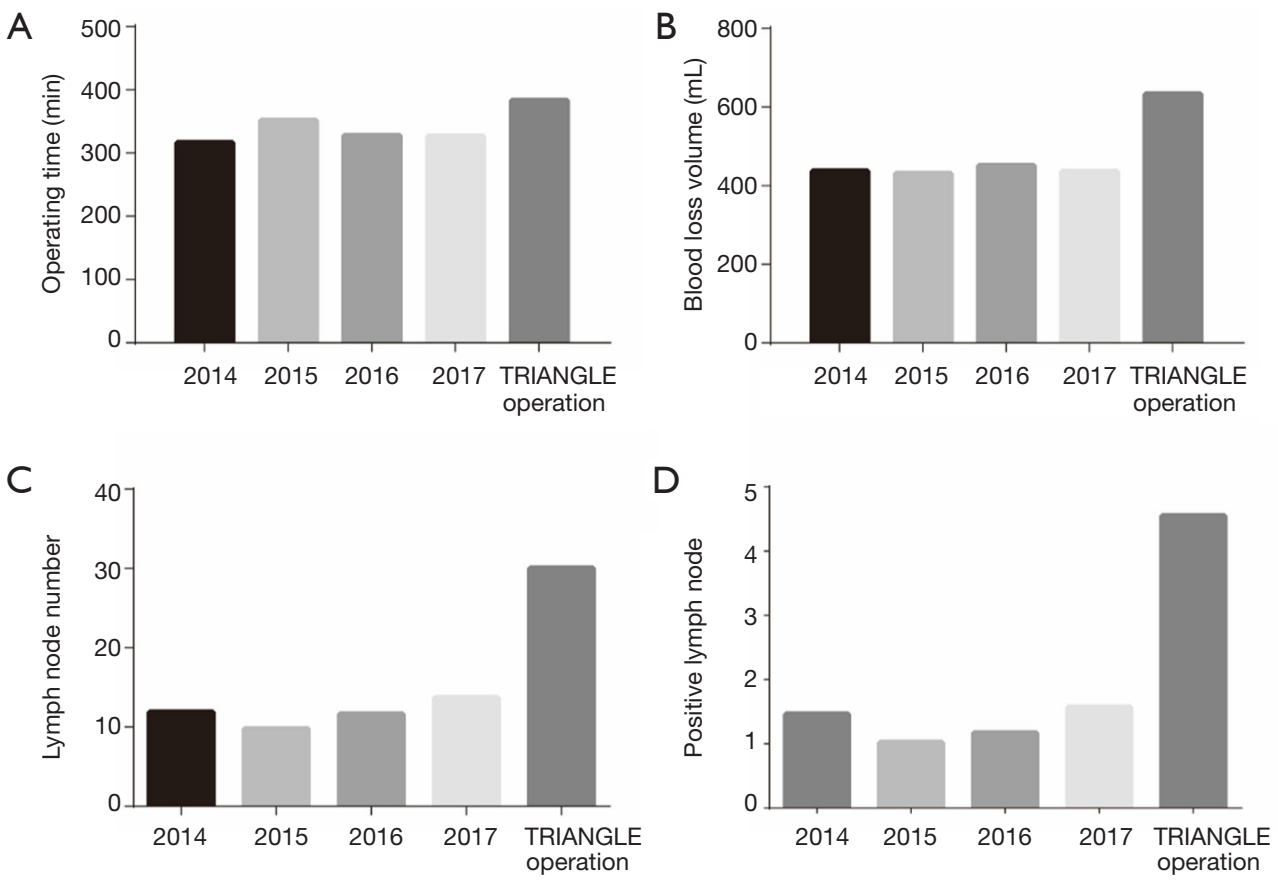

Figure 3 Perioperative data collected in recent years and in TRIANGLE operation. (A) Operating time, (B) blood loss, (C) lymph node number and (D) number of positive lymph node.

Table 3 Postoperative outcomes

\begin{tabular}{lc}
\hline Characteristics & Number \\
\hline Postoperative stay & $29[17-42]$ \\
Abnormal blood sugar after medication & 0 \\
Diarrhea & 2 \\
POPF & 0 \\
PPH & 0 \\
Hypokalemia & 0 \\
Lymphatic leak & 2 \\
Biliary fistula & 1 \\
Reoperation & 1 \\
Colon fistula & 1 \\
\hline
\end{tabular}

POPF, postoperative pancreatic fistula; $\mathrm{PPH}$, postoperative hemorrhage.

feature of this approach is the increased number of lymph nodes dissected in surgery and the positive lymph nodes among then. With the publication of the eighth edition of AJCC (22), biological behavior of tumor was addressed and $\mathrm{N}$ stage was revised. Patients with different number of positive lymph nodes have different prognosis. According to Figure 3, compared to the cases in 2014-2017 at our center, despite an increase in operating time and blood loss, the application of TRIANGLE operation results in more dissected lymph nodes and examining more positive lymph nodes. Recent evidence suggests that the detection rate of positive lymph node of pancreatic cancer is based on certain amount of lymph nodes dissected in surgery $(23,24)$. The clearance of lymph nodes, though it remains controversial in improving patients' prognosis, has more practical application in judging the stage of cancer and predicting the prognosis (25-27). Our postoperative hospital stay is longer because: (I) patients were discharged when they were fully recovered (absence of fever $>48 \mathrm{~h}$; able to take solid food; passage of normal stools; adequate mobilization; no drainage tube; acceptance of discharge by the patient). (II) patients would not be referred to community hospital.

The overall complication rate of resection of BRPC is high (28), but not in our approach which often requires vascular resection and reconstruction and excision of arterial sheath, which dramatically increase the risk of surgery. The common complications of pancreatic surgery are postoperative pancreatic fistula (POPF) and postoperative hemorrhage (PPH), which usually come together and have 
a causal relationship. POPF, intraperitoneal infection and $\mathrm{PPH}$ are regarded as lethal triad of pancreatic surgery. Fortunately, TP can prevent POPF, which is helpful to reduce the risk of hemorrhage caused by vascular resection, reconstruction and skeletonization. This approach has a large scale of lymph node dissection, so the incidence of lymphatic leak is higher. We have summarized two points on how to prevent lymphatic leak in this approach: (I) Protect the visible lymphatic vessels. (II) Every lymphatic leak should be ligated when we are checking after resecting.

The effect of TP on endocrine and exocrine function cannot be neglected. Patients who have an exocrine function disorder often suffer varying degrees of diarrhea, mostly fatty diarrhea. The reasons can be listed as follows: (I) The loss of exocrine function results in lack of multiple digestive enzymes. (II) The digestive tract is shortened by the excision of upper gastrointestinal tract and the time to digest is shortened accordingly. (III) The cut-off of autonomic nerves leads to hypersensitivity of digestive tract. All structures of the autonomous nerve system as well as all lymphatic tissue are dissected in the surgery, postoperative diarrhea or chyle leaks may occur. The complete dissection of nerves around SMA could result in refractory diarrhea which may reduce patient's quality of life. Thus, digestive enzymes and antidiarrheal should be provided. At present, this symptom is under good control through the internal medicine treatment. After TP, patients also will be devoid of insulin, the main hormones to regulate blood sugar, and present symptom of diabetes. It should be controlled with long-acting insulin, and strict diet, blood sugar monitoring also cannot be neglected. The glycemic control scheme in our study: 6-8 unit of long-acting insulin before sleep adjust with everyday blood sugar monitoring, is effective. Although TP results in the loss of endocrine and exocrine function, the modification of insulin preparation and application of pancreatin can dramatically improve the quality of life after surgery. Therefore, TP is not supposed to be restricted as it used to be, but to enlarge its scope of indication in pancreatic disease.

The perioperative outcomes of these 9 patients collected in the present study was good, in which there was no mortality and the morbidity rate was within acceptable limits. There was only one R1 resection which could not be avoided unless arterial resection and reconstruction was performed. Since arterial resection can be very risky and the application of adjuvant therapy in R1 situation may provide better outcomes than a merely palliative treatment (29), whether to routinely perform such operation, due to the high morbidity and mortality, has not reached an agreement $(25,30)$. Therefore, more investigations are needed to further assess the reliability and feasibility of TRIANGLE operation.

\section{Conclusions}

TRIANGLE operation is a possible method to achieve the radical resection of BRPC in patients who have not received neoadjuvant therapy. With TRIANGLE operation, arterial sparing resection can be achieved and the postoperative risk of POPF and PPH can be reduced. However, more studies are needed to further assess the reliability, feasibility and long-term effect of this operation.

\section{Acknowledgments}

We thank our anonymous reviewers for their valuable comments on this manuscript, which have led to much many improvements to the article.

Funding: This study was supported by grants from the Shanghai Anti-cancer Association (EYAS PROJECT; no. SACA-CY1C19).

\section{Footnote}

Conflicts of Interest: The authors have completed the ICMJE uniform disclosure form (available at http://dx.doi. org/10.21037/tcr.2019.09.50). The authors have no conflicts of interest to declare.

Ethical Statement: The authors are accountable for all aspects of the work in ensuring that questions related to the accuracy or integrity of any part of the work are appropriately investigated and resolved. The study was conducted in accordance with the Declaration of Helsinki (as revised in 2013). Informed consent from all participating patients and approval from the Ethics Committee of Shanghai Ruijin Hospital (No.172 in 2018) were obtained to conduct this research.

Open Access Statement: This is an Open Access article distributed in accordance with the Creative Commons Attribution-NonCommercial-NoDerivs 4.0 International License (CC BY-NC-ND 4.0), which permits the noncommercial replication and distribution of the article with the strict proviso that no changes or edits are made and the original work is properly cited (including links to both the 
formal publication through the relevant DOI and the license). See: https://creativecommons.org/licenses/by-nc-nd/4.0/.

\section{References}

1. Lin QJ, Feng Y, Chen J, et al. Current status and progress of pancreatic cancer in China. World J Gastroenterol 2015;21:7988-8003.

2. Sabater L, Muñoz E, Roselló S, et al. Borderline resectable pancreatic cancer. Challenges and controversies. Cancer Treat Rev 2018;68:124-35.

3. Varadhachary GR, Tamm EP, Abbruzzese JL, et al. BRPC: Definitions, Management, and Role of Preoperative Therapy. Ann Surg Oncol 2006;13:1035-46.

4. Hackert T, Strobel O, Michalski CW, et al. The TRIANGLE operation - radical surgery after neoadjuvant treatment for advanced pancreatic cancer: a single arm observational study. HPB (Oxford) 2017;19:1001-7.

5. Tempero MA, Malafa MP, Al-Hawary M, et al. Pancreatic Adenocarcinoma, Version 2.2017, NCCN Clinical Practice Guidelines in Oncology. J Natl Compr Canc Netw 2017;15:1028-61.

6. Hartwig W, Gluth A, Hinz U, et al. Total pancreatectomy for primary pancreatic neoplasms: renaissance of an unpopular operation. Ann Surg 2015;261:537-46.

7. National Comprehensive Cancer Network. NCCN clinical practice guidelines in oncology. Pancreatic adenocarcinoma. NCCN Guidelines version 3.2017.

8. Verbeke CS, Leitch D, Menon KV, et al. Redefining the R1 resection in pancreatic cancer. Br J Surg 2006;93:1232-7.

9. Bassi C, Marchegiani G, Dervenis C, et al. The 2016 update of the International Study Group (ISGPS) definition and grading of postoperative pancreatic fistula: 11 Years After. Surgery 2017;161:584-91.

10. Besselink MG, van Rijssen LB, Bassi C, et al. Definition and classification of chyle leak after pancreatic operation: A consensus statement by the International Study Group on Pancreatic Surgery. Surgery 2017;161:365-72.

11. Dindo D, Demartines N, Clavien PA. Classification of Surgical Complications. Ann Surg 2004;240:205-13.

12. Toesca DAS, Koong AJ, Poultsides GA, et al. Management of BRPC. Int J Radiat Oncol Biol Phys 2018;100:1155-74.

13. Bockhorn M, Uzunoglu FG, Adham M, et al. Borderline resectable pancreatic cancer: A consensus statement by the International Study Group of Pancreatic Surgery (ISGPS).
Surgery 2014;155:977-88.

14. Joo I, Lee JM, Lee ES, et al. Preoperative MDCT Assessment of Resectability in Borderline Resectable Pancreatic Cancer: Effect of Neoadjuvant Chemoradiation Therapy. AJR Am J Roentgenol 2018;210:1059-65.

15. Tosolini C, Michalski CW, Kleeff J. Response evaluation following neoadjuvant treatment of pancreatic cancer patients. World J Gastrointest Surg 2013;5:12-5.

16. Kumar R, Herman JM, Wolfgang CL, et al. Multidisciplinary management of pancreatic cancer. Surg Oncol Clin N Am 2013;22:265-87.

17. Shaib WL, Ip A, Cardona K, et al. Contemporary Management of Borderline Resectable and Locally Advanced Unresectable Pancreatic Cancer. Oncologist 2016;21:178-87.

18. Ielpo B, Duran H, Diaz E, et al. Preoperative treatment with gemcitabine plus nab-paclitaxel is a safe and effective chemotherapy for pancreatic adenocarcinoma. Eur J Surg Oncol 2016;42:1394-400.

19. Katz MH, Shi Q, Ahmad SA, et al. Preoperative Modified FOLFIRINOX Treatment Followed by CapecitabineBased Chemoradiation for BRPC: Alliance for Clinical Trials in Oncology Trial A021101. JAMA Surg 2016;151:e161137.

20. Murakami Y, Uemura K, Sudo T, et al. Survival impact of neoadjuvant gemcitabine plus S-1 chemotherapy for patients with borderline resectable pancreatic carcinoma with arterial contact. Cancer Chemother Pharmacol 2017;79:37-47.

21. Hackert T, Sachsenmaier M, Hinz U, et al. Locally Advanced Pancreatic Cancer: Neoadjuvant Therapy With Folfirinox Results in Resectability in $60 \%$ of the Patients. Ann Surg 2016;264:457-63.

22. Allen PJ, Kuk D, Castillo CF, et al. Multi-institutional Validation Study of the American Joint Commission on Cancer (8th Edition) Changes for $\mathrm{T}$ and $\mathrm{N}$ Staging in Patients With Pancreatic Adenocarcinoma. Ann Surg 2017;265:185-91.

23. Malleo G, Maggino L, Ferrone CR, et al. Number of Examined Lymph Nodes and Nodal Status Assessment in Distal Pancreatectomy for Body/Tail Ductal Adenocarcinoma. Ann Surg 2018. [Epub ahead of print]

24. Faron M, Vuarnesson H, Boher JM, et al. How to Reliably Assess Nodal Status in Distal Pancreatectomy for Adenocarcinoma. Pancreas 2018;47:308-13.

25. Huebner M, Kendrick M, Reid-Lombardo KM, et al. Number of lymph nodes evaluated: prognostic value 
in pancreatic adenocarcinoma. J Gastrointest Surg 2012;16:920-6.

26. Vuarnesson H, Lupinacci R M, Semoun O, et al. Number of examined lymph nodes and nodal status assessment in pancreaticoduodenectomy for pancreatic adenocarcinoma. Eur J Surg Oncol 2013;39:1116-21.

27. Shi S, Hua J, Liang C, et al. Proposed Modification of the 8th Edition of the AJCC Staging System for Pancreatic Ductal Adenocarcinoma. Ann Surg 2019;269:944-50.

Cite this article as: Zhai S, Huo Z, Wang Y, Qian H, Zhao S, Shi Y, Weng Y, Deng X, Shen B. TRIANGLE operation for borderline resectable pancreatic cancer in total pancreatectomy. Transl Cancer Res 2019;8(6):2416-2424. doi: 10.21037/ tcr.2019.09.50
28. Kasumova GG, Conway WC, Tseng JF. The Role of Venous and Arterial Resection in Pancreatic Cancer Surgery. Ann Surg Oncol 2018;25:51-8.

29. Konstantinidis IT, Warshaw AL, Allen JN, et al. Pancreatic ductal adenocarcinoma: is there a survival difference for $\mathrm{R} 1$ resections versus locally advanced unresectable tumors? What is a "true" R0 resection? Ann Surg 2013;257:731-6.

30. Mollberg N, Rahbari NN, Koch M, et al. Arterial resection during pancreatectomy for pancreatic cancer: a systematic review and meta-analysis. Ann Surg 2011;254:882-93. 